\title{
Impact of climate changes on food safety related issues in the case of Romania
}

\author{
Mihaela Cristina Drăgoi ${ }^{1,}{ }^{*}$ and Irina Gabriela Rădulescu ${ }^{2}$ \\ ${ }^{1}$ Center of International Business and Economics (CCREI), Faculty of International Business and \\ Economics, The Bucharest University of Economic Studies, 6 Piata Romana, 1st district, 010374, \\ Bucharest, Romania \\ ${ }^{2}$ Department of Business Administration, Faculty of Economic Sciences, Petroleum-Gas University \\ of Ploiești, 39 Bucuresti Blvd., 100680, Ploiesti, Prahova, Romania
}

\begin{abstract}
Climate change and economic development have both an increasing impact on human health and on the quality of life. The reverse assumption is also true, since, for improving economic and social development and well-being, the human activity is affecting the environment. This paper presents some of the alarm signals of various international institutions and entities regarding several challenges the current modern society is facing: climate change, disruptive weather events, food safety implications, health related issues, economic losses. Based on previous studies which demonstrated a direct connection between climate changes and weather conditions and the outbreak of infectious diseases and threats for the food safety chain, the main research objective is to determine whether this hypothesis is also valid in the case of Romania. Thus, the conducted analysis takes into consideration variations of temperature and precipitation in relation to new cases of food-borne diseases in order to determine if this connection is statistically significant as it was in other regions of Europe and of the world previously examined by scholars.
\end{abstract}

Keywords: climate change, food safety, food-borne diseases, economic costs

JEL Classification: $C 12, F 60, Q 51$

\section{Introduction}

Climate change is an emerging danger that creates additional stress on vulnerable points in the health care system, which implies increased attention from policy makers and a reconsideration of public health priorities. Development of environmental management, changes in infectious disease patterns, and the strengthening of health protection against natural disasters could be one of the solutions to improve human health [1].

Climate is constantly changing globally and has an important impact on human society. According to a study conducted by the Intergovernmental Panel on Climate Change, global

* Corresponding author: mihaelacristina.dragoi@gmail.com 
warming observed since the mid-20th century was due to greenhouse gas emissions from human activities, in particular agriculture, land use change and combustion of fossil fuels.

Even if these global emissions will be substantially reduced, the impact of climate change will be felt worldwide on our health, economy and ecosystems; this is why a more dynamic approach is needed to avoid costly impacts on infrastructure, property and health. Also, there is a pressing need to adapt to climate change, given that mitigation cannot prevent its impact.

Both at global and European scale it has been observed over time that the number and magnitude of climate-related events has largely changed due to human activities. According to [2], about $75 \%$ of moderate-daily hot extremes are linked to human activity and continue to grow. Since 1980, record-breaking rainfall events have increased at the same time with rising temperatures [3] and the probability and magnitude of individual climate-related events have been correlated with the anthropogenic climate change [4].

Climate change has a significant impact on population health through direct physical effects and indirect changes in the economic and social spheres. The indirect impact of climate change, correlated with socio-demographic changes, leads to a number of indirect health effects amplified by increased conflicts, disruptions and dislocations in society: infectious disease risks and health problems [5].

Climate change brings challenges to the supply of sanitation services and sustainable water, especially in Europe. Nearly half of the infectious diseases reported by the EU annually are related to climate change [6], and many vector-borne diseases are considered to be a priority for the EU. In most cases, the climate change effect on the health of the population depends on its vulnerability. In the EU, there is a variation of vulnerable areas between regions, only some of these areas having the capacity to adapt and mitigate certain climate change-related risks. Areas with a high risk of transmission of infectious diseases include regions from Greece, Romania, Bulgaria and Southern Italy [7]. The main health risks associated with climate change that have been identified in Europe are shown in Figure 1.

In accordance with [8], seasonal changes, rising temperatures or extreme precipitation events related to climate change have a significant impact on food-borne diseases in Europe. These climatic factors can contaminate drinking, irrigation, and recreational water, increasing pathogens and disrupting the water treatment system. High air temperatures can have adverse effects on food during transport as well as handling and storage.

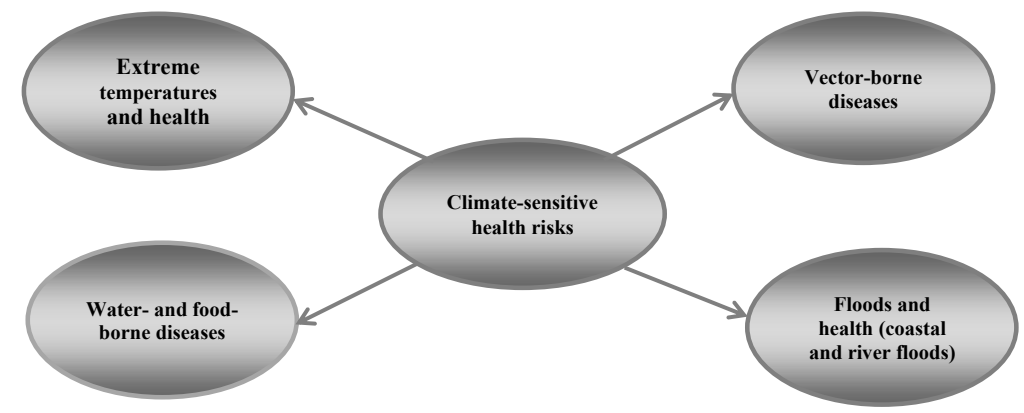

Fig. 1. Key climate-sensitive health risks

Source: [9]

Salmonellosis is one of the main causes of food-borne outbreaks, being one of the most commonly reported in Europe, and the main alarm signal of the World Health Organization is that in EU countries, Salmonella and Campylobacter show significant levels of resistance to common antimicrobials used in humans and animals. The increase in weekly temperature 
was associated with an increase in Salmonellosis in different regions [10], as well as extreme precipitation events [11]. Exposure to Salmonellosis can also be caused by strong floods that can disrupt water treatment and sewage systems [9]. In the future, the number of annual Salmonellosis cases is predicted to increase by nearly 20,000 by 2030 and if we are considering a pessimistic scenario, climate change may result in a $50 \%$ increase in temperature-related cases. However, there is some uncertainty about these projections [12] that also comes from alleviating the negative effects through better health promotion and implementing effective food safety policies.

Nevertheless, international studies show that apart from the people living in poverty, which are the most exposed to food-borne health risks, demographic and environmental developments, such as increasing migration, climate change and extreme weather events are putting more people at risk [13]. Food safety issues have become more stringent over the past decades [14], since the globalization of the food and animal trade leads to a wider variety of food available to consumers, also making the food chain even longer and more complex, thus creating an environment where known and new food-borne diseases, hazards and risks may spread more easily [13].

As analyzed literature has emphasized for various regions of the world, there is a direct link between climatic events and changes and outbreaks and transmission of food-borne diseases, especially for Salmonellosis case. Our paper's main objective is to verify this hypothesis in the case of Romania, since no previous studies have conducted such an analysis attempt. The originality of this study resides in collecting available health and meteorological data and analyzing the extent to which these two kinds of indicators are statistically relevant for the broad issue of climate change and food safety. The Introduction of the paper highlights the main considerations our analysis is based upon, emphasizing the main frame regarding climate changes' causes and effects on economic and social development. The second section of the paper presents the methodology employed for data collection and investigation, while also explaining methodological limitations due to lack of available information on health indicators at national level. The third part of the paper details the results of the conducted analysis and discussion on several aspects which show relevance to the scope of the research. The last section presents the main conclusions of the study and further directions of research emerged from the results of the current analysis.

\section{Material and methodology}

As formerly stated, the paper aims at emphasizing the connection between various environmental factors and food-borne diseases. Previous studies [6,8,15-22] have shown a certain level of correlation between temperature and precipitation and the number of acute diarrheal diseases, especially Salmonellosis cases; therefore, we have also tested this hypothesis in the case of Romania, as part of the European Single Market provisions demand and offer.

According to the NUTS 2013 classification which is valid from $1^{\text {st }}$ of January 2015, Romania is divided into four major socio-economic regions (NUTS 1 level) and eight development regions (NUTS 2 level). At NUTS 3 level, namely at local administrative level, Romania consists of 41 counties and the capital city Bucharest, which has an individual administrative status.

In order to pursue our analysis regarding the influence of climate factors on the outbreak of infectious diseases, we have addressed enquiries regarding available information to the Public Health Directorates in all regions. However, health data is collected in an extended manner only for a limited number of counties called sentinel counties. Therefore, in Romania's case, health data was available for the counties of Tulcea, Constanța, Galați and Brăila, which are all part of the Sud-Est (South-East) 
development region. The main reasons for having these particular counties as sentinel ones are that, on one hand, the climate has more accentuated phases in this area and, on the other hand, the proximity to the border makes them more prone to contracting new waves of infection, due to the fact that thousands of persons and tones of goods enter the country through the Black Sea shore each year.

As other studies have shown, climate variations generate food-borne diseases, especially acute diarrheal diseases, associated with infectious bacteria such as Salmonella, Rotavirus or E.coli; among them, Salmonella is one of the most common causes for acute diarrheal diseases and is one of the indicators we used in our analysis. Moreover, these bacteria are known to spread faster during rainy periods of time or during droughts.

Therefore, for each of the four counties we collected weekly data regarding the temperature, the amount of precipitation, the number of new cases of acute diarrheal diseases and the Salmonellosis cases among them. Weekly available data in the case of acute diarrheal diseases comprised the months of summer, when most cases are registered, therefore we were determined to limit the weekly time series to 22 or 23 weeks each year, starting with the first week of June and ending with the last week of October; the years taken into consideration are 2016, 2017 and 2018, resulting in a total of 67 weeks subject to analysis. Subsequently, since health data was available for this time frame only, the data regarding temperature and precipitation ranged accordingly.

In terms of temperature, we took into analysis both the maximum temperature (measured in Celsius degrees) and the average temperature recorded for each week. Similarly, for the case of precipitation, the data range accounted for the total weekly precipitation and the average weekly precipitation, respectively. All information regarding the new weekly cases of acute diarrheal diseases was available from the Romanian National Institute of Public Health - The National Center for Communicable Disease Surveillance and Control and the National Institute of Statistics, while the meteorological information was provided by the National Administration of Meteorology.

Subsequently, for all the weeks taken into analysis, the number of new cases of acute diarrheal diseases and the number of new cases of Salmonellosis have been used as independent variables against temperature and precipitation-related dependent variables and linear regression models were run. For the ease of testing, each variable was attributed a shortened notation, as presented in Table 1.

Table 1. Explanatory variables used in the regression models

\begin{tabular}{|c|c|}
\hline \multicolumn{2}{|c|}{ Independent variables } \\
\hline Indicator & Notation \\
\hline Weekly new cases of acute diarrheal diseases & ADD \\
\hline Weekly new cases of Salmonellosis & SalCases \\
\hline \multicolumn{2}{|l|}{ Dependent variables } \\
\hline Indicator & Notation \\
\hline Weekly average temperature $\left({ }^{\circ} \mathrm{C}\right)$ & AvTemp \\
\hline Weekly maximum temperature $\left({ }^{\circ} \mathrm{C}\right)$ & MaxTemp \\
\hline Average weekly precipitation (mm) & AvPrec \\
\hline Total weekly precipitation (mm) & TotPrec \\
\hline
\end{tabular}

The main aim of the study was to determine whether the hypothesis that meteorological conditions affect the outbreak of food-borne infectious diseases, as other studies have proved for various regions of the world. Since acute diarrheal diseases, especially 
Salmonella infections have been related to excessive temperature and precipitation, the regression models conducted for each of the four counties considered these as independent variables. Both new acute diarrheal diseases and new Salmonellosis cases were run against the four dependent variables presented before, which were divided into two groups: 1) weekly average temperature and average weekly precipitation and 2) weekly maximum temperature and total weekly precipitation. Thus, a linear regression was used, and several regression models were conducted, in order to test each of the independent variable against each group of dependent variables for each of the four counties taken into consideration. The corresponding correlation matrix is presented in Table 2 and confirms that the two groups are correctly divided, since the level of correlation among the dependent variables of each group is less than 0.4 , thus eliminating bias coefficients for the independent variables.

Table 2. The correlation matrix

\begin{tabular}{|ccccc|}
\hline & AvTemp & AvPrec & MaxTemp & TotPrec \\
\hline AvTemp & 1 & & & \\
\hline AvPrec & -0.32659 & 1 & & \\
\hline MaxTemp & 0.92056 & -0.29666 & 1 & \\
\hline TotPrec & -0.32759 & 0.999836 & -0.29705 & 1 \\
\hline
\end{tabular}

However, the results for each regression model conducted in order to determine the influence of climatic factors on the outbreak of food-borne diseases proved insignificant. The main findings regarding the county of Tulcea are comprised in Table 3. The results for the other three counties of Constanța, Brăila and Galaţi are similar and inconclusive.

The regression models tested, at a $95 \%$ confidence level, the influence of the average temperature and average amount of precipitation on the outbreak of new ADD and Salmonellosis cases as well as the influence of high temperatures and total amount of precipitation on these food-borne diseases.

Table 3. Regression results for the county of Tulcea (NUTS 3 level)

\begin{tabular}{|c|c|c|c|c|c|c|}
\hline & \multirow{2}{*}{\multicolumn{3}{|c|}{ ADD }} & \multirow{2}{*}{\multicolumn{3}{|c|}{ SalCases }} \\
\hline & & & & & & \\
\hline & Coefficients & P-value & $\mathrm{R}^{2}$ & Coefficients & P-value & $\mathrm{R}^{2}$ \\
\hline Intercept & 3.739031 & 0.183346 & 0.0481 & 0.516138 & 0.315988 & 0.0668 \\
\hline AvTemp & 0.228653 & 0.076972 & \multirow{2}{*}{$\begin{array}{c}\text { Not } \\
\text { significant }\end{array}$} & 0.048484 & 0.042046 & \multirow{2}{*}{$\begin{array}{c}\text { Not } \\
\text { significan }\end{array}$} \\
\hline \multirow[t]{3}{*}{ AvPrec } & 0.270981 & 0.545974 & & 0.014843 & 0.856947 & \\
\hline & \multicolumn{3}{|c|}{ ADD } & \multicolumn{3}{|c|}{ SalCases } \\
\hline & Coefficients & P-value & $\mathrm{R}^{2}$ & Coefficients & $\mathrm{P}$-value & $\mathrm{R}^{2}$ \\
\hline Intercept & 0.729118 & 0.845675 & 0.0671 & 0.077814 & 0.910603 & 0.0724 \\
\hline MaxTemp & 0.258615 & 0.035729 & \multirow{2}{*}{$\begin{array}{c}\text { Not } \\
\text { significant }\end{array}$} & 0.048197 & 0.03446 & \multirow{2}{*}{$\begin{array}{c}\text { Not } \\
\text { significan }\end{array}$} \\
\hline TotPrec & 0.037954 & 0.545709 & & 0.001149 & 0.921147 & \\
\hline
\end{tabular}

We have also ran the same tests with a one-day lag and two-days lag, since Salmonella and other bacteria which determine food-borne diseases have an incubation period that can generate health effects ranging from a few hours to two days. Nonetheless, the findings show no significant influence of the selected dependent variables on the outbreak of ADD 
cases. Since there is no available health data for all Romanian counties, but only for the four sentinel counties taken into analysis, it is impossible to predict whether climatic variations would determine more statistically significant results in the case of other regions of the country. For a more thorough scientific investigation, local authorities should collect, store, and disseminate towards researchers and academia such data on a regular basis, even though it could translate into higher workload for their staff.

\section{Results and discussion}

Even though the hypothesis of a noteworthy influence of climatic factors on development of bacteria which determine food-borne diseases was not confirmed for the four sentinel counties of Romania, the fact that these cases are accounted for the weeks of spring, summer and autumn without including the weeks of winter validate the fact that these bacteria, especially Salmonella, are growing slow at temperatures below $10{ }^{\circ} \mathrm{C}$; moreover, reports suggesting that some serotypes can grow at temperatures as low as $4{ }^{\circ} \mathrm{C}$ are not even universally accepted [23]. Also, albeit the regression models turned out to be statistically insignificant, the most cases of such infections were recorded for the hotter weeks of the months of July and August, when the temperature/humidity index exceeded the critical threshold of 80 units, thus confirming findings of previous studies regarding the direct connection between high temperature and humid environments and development of infectious bacteria (Salmonella for instance is known to not be able to grow in dry environments).

Therefore, since high temperature and humidity do not represent statistically significant factors for the outbreak of food-borne diseases in the case of Romania, this means that there are other factors to consider in determining such phenomena. It is a known fact that many foods of animal origin, such as meat, poultry, eggs, and raw milk can become contaminated. Salmonella may also contaminate fresh produce via contact with infected animals or other environmental sources [23]. In terms of preventing the spread of infections, food safety and clean food production become national and international issues, as previously emphasized by [14]. Many countries have policies that encourage measures to reduce the levels of Salmonella and other bacteria in egg production units, in poultry houses, during the growing of fresh produce and also during transport of raw commodities [23]. Food manufacturers must take into serious consideration obtaining their food ingredients supplies from producers which have implemented active controls or deliver pasteurized products in the case of dairy products and eggs. These aspects are of high importance especially for resulting food products which will afterwards be consumed as such, without prior cooking. Moreover, the need of careful handling and correct storage both at retailers' facilities and at consumers' homes must be emphasized, as well as working in clean environments with clean hands and equipment when handling raw or processed food products.

Conversely, as stated by the World Health Organization Regional Office for Europe, another issue arises, respectively the fact that over sixty-seven million Europeans lack access to improved sources of drinking-water and sanitation facilities, as defined by the WHO/UNICEF Joint Monitoring Programme for Water Supply and Sanitation; the European region must address the gaps and disparities among regions, especially in rural areas, and thus improving human health and reducing the risk of infections.

Moreover, climate related extreme events caused economic losses of $€ 436$ billion between 1980 and 2016 for the European Economic Area's countries, which represents an increase over previous periods [24]. This growth is closely linked to socio-economic trends such as human activities, infrastructure in prone areas and population changes, as well as heavy rainfall in some regions of Europe. Annual variations in climate events and the 
implementation of mitigation measures hinder the correlation between climate changes and associated economic losses. Better data collection on the social, economic, and environmental impacts of climate change could lead to far more appropriate policies and measures.

According to the European Environment Agency, economic damage caused by weather and climate-related extreme events was $€ 20,166$ billion (at 2016 values): $€ 10,442$ billion from geophysical events, €2,849 billion from meteorological events, €6,194 billion from hydrological events and $€ 681$ billion from climatological events. The largest losses in absolute value were registered in France (€60,043 million), Italy (€61,778 million) and Germany (€92,144 million); the highest losses per capita in Denmark $(€ 1,868)$, Switzerland $(€ 2,580)$ and Luxembourg $(€ 1,605)$, and those expressed as an insurance losses percentage were recorded in United Kingdom (70\%), Denmark (61\%), Belgium and Hungary (59\%) [24].

\section{Conclusions}

Although the research results do not confirm the hypothesis for which the study was conducted, we believe that food-borne diseases remain a problem in Romania and should be monitored further. We appreciate that this result needs to be analyzed also in comparison with other studies conducted in the other EU member states. In addition, all environmental factors that influence human well-being and which have a direct and indirect impact on the health of the people should be monitored.

In order to achieve more conclusive results, there should be a harmonization of the considered indicators and their introduction into the environmental policy of Romania. One of the possible solutions for reducing food-borne diseases could be to improve risk factors by preventing, educating, and properly informing the population.

The issue of clean production, handling, delivery, and consumption of food products, especially of raw ones, is of high importance not only for the European Union countries, but for various countries and organizations throughout the world. The European Single Market as well as the globalization process allow commodities to circulate easier thus foodborne diseases are more easily spread if preventive measures and actions are not taken.

In almost all regions the effects of climate change on the market are predicted to be negative, with significant risks of tipping points. In the future, the market's impact is projected to have macroeconomic costs ranging from $1.0 \%$ to $3.3 \%$ of annual GDP by 2060 , and by the end of the century to reach $10 \%$ [25] given that existing environmental policies will not be revised and adapted to current environmental conditions.

Even if available data and variables used for testing the initial hypothesis proved to be inconclusive, available literature emphasizes the effects of climate changes on economic and social well-being of a region or country in general, without overlooking the implications of food safety threats on markets and consumers. Climate-related and foodborne diseases affect various regions of Europe and of the world due to the constant globalization process and the free movement of goods and persons, translating into losses at all economic and social levels:

- For the economy, as stakeholders involved in manufacturing, transporting, or handling affected products lose an important income

- For the governmental entities, which must take all necessary actions to prevent and treat various outbreaks

- For the society, as health issues determine decreases on the long-run in the qualityadjusted life years.

In order to address the limitations of the current analysis and to become relevant for the case of Romania, further research should take into consideration a wider array of indicators 
which could enlarge the panel of determining factors of food safety related diseases, such as access to quality water sources, sanitation, food purchasing and eating habits, the dimension of food supply chain etc., since only climatic factors did not confirm our research hypothesis, as in the case of other countries analyzed in previous literature. Additionally, the above-mentioned losses can be expressed in monetary terms, hence evaluating the economic costs of the impact of climate change on the food safety and health-related issues; such extended endeavor remains under the scope of the authors for a future research work.

\section{References}

1. World Health Organization Regional Office for Europe. (2015). Improving environment and health in Europe: how far have we gotten? http://www.euro.who.int/_data/assets/pdf_file/0018/276102/Improvingenvironment-health-europe-en.pdf?ua $=1$

2. Fischer, E. M., \& Knutti, R. (2015). Anthropogenic contribution to global occurrence of heavy-precipitation and high-temperature extremes. Nature Climate Change, 5(6), 560-564. https://doi.org/10.1038/nclimate2617

3. Lehmann, J., Coumou, D., \& Frieler, K. (2015). Increased record-breaking precipitation events under global warming. Climatic Change, 132(4), 501-515. https://doi.org/10.1007/s10584-015-1434-y

4. Christidis, N., Jones, G. S., \& Stott, P. A. (2015). Dramatically increasing chance of extremely hot summers since the 2003 European heatwave. Nature Climate Change, 5(1), 46-50. https://doi.org/10.1038/nclimate2468

5. McMichael, A. J. (2013). Globalization, Climate Change, and Human Health. New England Journal of Medicine, 368(14), 1335-1343. https://doi.org/10.1056/NEJMra1109341

6. Lindgren, E., Andersson, Y., Suk, J. E., Sudre, B., \& Semenza, J. C. (2012). Monitoring EU Emerging Infectious Disease Risk Due to Climate Change. Science, 336(6080), 418-419. https://doi.org/10.1126/science.1215735

7. Suk, J., Ebi, K., Vose, D., Wint, W., Alexander, N., Mintiens, K., \& Semenza, J. (2014). Indicators for Tracking European Vulnerabilities to the Risks of Infectious Disease Transmission due to Climate Change. International Journal of Environmental Research and Public Health, 11(2), 2218-2235. https://doi.org/10.3390/ijerph110202218

8. Semenza, J. C., Suk, J. E., Estevez, V., Ebi, K. L., \& Lindgren, E. (2012). Mapping climate change vulnerabilities to infectious diseases in Europe. Environmental Health Perspectives, 120(3), 385-392. https://doi.org/10.1289/ehp.1103805

9. European Environment Agency. (2017). Climate change, impacts and vulnerability in Europe 2016. An indicator-based report. https://doi.org/10.2800/534806

10. Nichols, G., Lane, C., Asgari, N., Verlander, N. Q., \& Charlett, A. (2009). Rainfall and outbreaks of drinking water related disease and in England and Wales. Journal of Water and Health, 7(1), 1-8. https://doi.org/10.2166/wh.2009.143

11. Craig, D. L., Fallowfield, H. J., \& Cromar, N. J. (2003). Effectiveness of guideline faecal indicator organism values in estimation of exposure risk at recreational coastal sites. Water Science and Technology: A Journal of the International Association on Water Pollution Research, 47(3), 191-198. http://www.ncbi.nlm.nih.gov/pubmed/12639028

12. Watkiss, P., \& Hunt, A. (2012). Projection of economic impacts of climate change in sectors of Europe based on bottom up analysis: human health. Climatic Change, 112(1), 101-126. https://doi.org/10.1007/s10584-011-0342-z 
13. World Health Organization Regional Office for Europe. (2015). Food safety in the WHO European Region. Food Safety Fact Sheet. http://www.euro.who.int/_data/assets/pdf_file/0003/274467/fact-sheet-whd2015en.pdf?ua $=1$

14. Drăgoi, M. C., Andrei, J. V., Mieilă, M., Panait, M., Dobrotă, C. E., \& Lădaru, R. G. (2018). Food Safety and Security in Romania - An Econometric Analysis in the Context of National Agricultural Paradigm Transformation. Amfiteatru Economic, 20(47), 134-150. https://doi.org/10.24818/EA/2018/47/134

15. Bentham, G., \& Langford, I. H. (1995). Climate change and the incidence of food poisoning in England and Wales. International Journal of Biometeorology, 39(2), 81-86. https://doi.org/10.1007/BF01212585

16. Chhetri, B. K., Galanis, E., Sobie, S., Brubacher, J., Balshaw, R., Otterstatter, M., Mak, S., Lem, M., Lysyshyn, M., Murdock, T., Fleury, M., Zickfeld, K., Zubel, M., Clarkson, L., \& Takaro, T. K. (2019). Projected local rain events due to climate change and the impacts on waterborne diseases in Vancouver, British Columbia, Canada. Environmental Health, 18(1), 116. https://doi.org/10.1186/s12940-019-0550y

17. Cissé, G. (2019). Food-borne and water-borne diseases under climate change in lowand middle-income countries: Further efforts needed for reducing environmental health exposure risks. Acta Tropica, 194, 181-188. https://doi.org/10.1016/j.actatropica.2019.03.012

18. European Centre for Disease Prevention and Control. (2020). Climate change in Europe. https://ecdc.europa.eu/en/climate-change/climate-change-europe

19. Lal, A., Ikeda, T., French, N., Baker, M. G., \& Hales, S. (2013). Climate Variability, Weather and Enteric Disease Incidence in New Zealand: Time Series Analysis. PLOS ONE, 8(12), e83484. https://doi.org/10.1371/journal.pone.0083484

20. Miraglia, M., Marvin, H. J. P., Kleter, G. A., Battilani, P., Brera, C., Coni, E., Cubadda, F., Croci, L., De Santis, B., Dekkers, S., Filippi, L., Hutjes, R. W. A., Noordam, M. Y., Pisante, M., Piva, G., Prandini, A., Toti, L., van den Born, G. J., \& Vespermann, A. (2009). Climate change and food safety: An emerging issue with special focus on Europe. Food and Chemical Toxicology, 47(5), 1009-1021. https://doi.org/10.1016/j.fct.2009.02.005

21. Smith, B. A., Meadows, S., Meyers, R., Parmley, E. J., \& Fazil, A. (2019). Seasonality and zoonotic foodborne pathogens in Canada: relationships between climate and Campylobacter, E . coli and Salmonella in meat products. Epidemiology and Infection, 147, e190. https://doi.org/10.1017/S0950268819000797

22. Zhang, Y. (2007). The Relationship between Climate Variation and Selected Infectious Diseases: Australian and Chinese Perspectives. PhD Thesis: The University of Adelaide.

23. Lawley, R. (2013). Salmonella. Food Safety Watch. The Science of Safe Food. http://www.foodsafetywatch.org/factsheets/salmonella/

24. European Environment Agency. (2017). Economic losses from climate-related extremes. Climate Change Adaptation. https://www.eea.europa.eu/data-andmaps/indicators/direct-losses-from-weather-disasters-3/assessment-1

25. OECD. (2015). The Economic Consequences of Climate Change. OECD Publishing. https://doi.org/10.1787/9789264235410-en 